\title{
A pilot protocol and review of triple neuroprotection with targeted hypothermia, controlled induced hypertension, and barbiturate infusion during emergency carotid endarterectomy for acute stroke after failed tPA or beyond 24-hour window of opportunity
}

\author{
Sherif Sultan ${ }^{1,2}$, Yogesh Acharya ${ }^{1}$, Nora Barrett ${ }^{1}$, Niamh Hynes ${ }^{2}$ \\ ${ }^{1}$ Western Vascular Institute, Department of Vascular and Endovascular Surgery, University Hospital Galway, National University of Ireland, Galway, \\ Ireland; ${ }^{2}$ Department of Vascular \& Endovascular Surgery, Galway Clinic, Royal College of Surgeons of Ireland/National University of Ireland \\ Affiliated Teaching Hospitals, Doughiska, Galway, Ireland \\ Contributions: (I) Conception and design: S Sultan; (II) Administrative support: S Sultan, N Barrett; (III) Provision of study materials or patients: \\ All authors; (IV) Collection and assembly of data: Y Acharya, N Hynes; (V) Data analysis and interpretation: Y Acharya, N Hynes; (VI) Manuscript \\ writing: All authors; (VII) Final approval of manuscript: All authors. \\ Correspondence to: Prof. Sherif Sultan, MCh, MD, FRCS, FACS, PhD. Professor of Vascular Surgery, National University of Ireland Galway, Ireland. \\ Email: sherif.sultan@hse.ie.
}

\begin{abstract}
An alternative to tissue plasminogen activator (tPA) failure has been a daunting challenge in ischemic stroke management. As tPA is time-dependent, delays can occur in definitive treatment while passively waiting to observe a clinical response to intravenous thrombolysis. Until today, uncertainty exists in the management strategy of wake-up stroke patients or those presenting beyond the therapeutic tPA window. Clinical dilemmas in these situations can prolong the transitional period of inertia, resulting in an adverse neurological outcome. We propose and review an innovative approach called triple neuro-protection (TNP), which encompasses three technical domains-targeted hypothermia, systemic induced hypertension, and barbiturates infusion, to protect the brain during carotid endarterectomy after failed tPA and/or beyond the 24-hour therapeutic mechanical thrombectomy window. This proposal assimilates discussion on the clinical evidence of the individual domains of TNP with our own clinical experience with TNP. Our first TNP was successfully employed in a 55-year-old man in 2015 while performing emergency carotid endarterectomy after he was referred to us 72 hours post tPA failure. The patient had a successful clinical outcome despite being in therapeutic inertia with 90-99\% ipsilateral carotid stenosis and contralateral occlusion on presentation. In the last five years, we have safely used TNP in 25 selected cases with favourable clinical outcomes.
\end{abstract}

Keywords: Triple neuroprotection; therapeutic hypothermia; induced hypertension; barbiturates; stroke; ischemia; review

Submitted Feb 02, 2020. Accepted for publication Apr 30, 2020.

doi: $10.21037 / \mathrm{atm}-2020$-cass-14

View this article at: http://dx.doi.org/10.21037/atm-2020-cass-14

\section{Introduction}

Tissue plasminogen activator ( $\mathrm{tPA})$ is an established therapy for acute stroke, but its success and therapeutic range is limited. However, therapeutic alternatives to tPA have been a daunting question in ischemic stroke management. The addition of mechanical thrombectomy is well established in patients with internal carotid artery (ICA), or proximal middle cerebral artery (M1), occlusion, as demonstrated by studies including Multicenter Randomized Clinical Trial of Endovascular Treatment for Acute Ischemic Stroke in the Netherlands (MR CLEAN) (1), Solitaire ${ }^{\mathrm{TM}}$ With the 


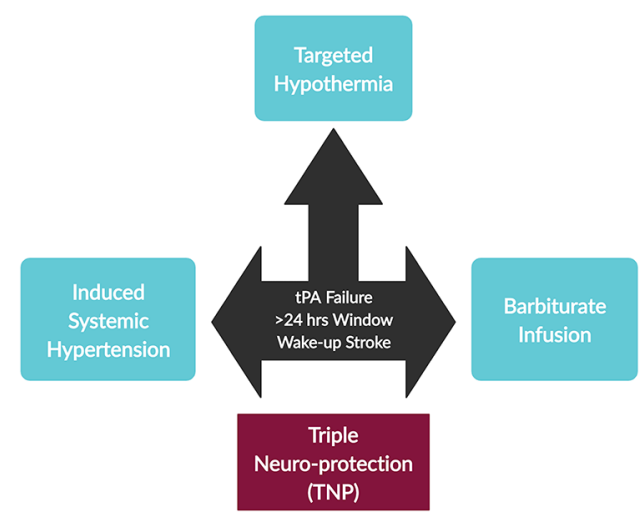

Figure 1 Three components of triple neuro-protection: targeted hypothermia, induced systemic hypertension, and barbiturate infusion.

Intention For Thrombectomy as PRIMary Endovascular Treatment (SWIFT PRIME) (2), Extending the Time for Thrombolysis in Emergency Neurological Deficits-IntraArterial (EXTEND-IA) (3), Endovascular Treatment for Small Core and Anterior Circulation Proximal Occlusion with Emphasis on Minimizing CT to Recanalization Times (ESCAPE) (4), Randomized Trial of Revascularization with Solitaire FR Device versus Best Medical Therapy in the Treatment of Acute Stroke Due to Anterior Circulation Large Vessel Occlusion Presenting within Eight Hours of Symptom Onset (REVASCAT) (5) and Mechanical Thrombectomy After Intravenous Alteplase Versus Alteplase Alone After Stroke (THRACE) (6). However, not all patients show clinical improvement following thrombectomy (7), and the outcome after thrombectomy declines with more extended latent periods from symptoms to arterial puncture $(8,9)$. Time is Brain $(10)$, and each one-hour delay in reperfusion is invariably associated with worsening disability. Clinical dilemmas in these situations can compromise the neurological outcome. To overcome these practical challenges, we propose an innovative alternative approach in patients undergoing emergency carotid endarterectomy (CEA) after failed tPA and/or beyond the 24-hour therapeutic mechanical thrombectomy window.

\section{Triple neuroprotection (TNP)}

TNP is a technique employed to protect the brain through targeted hypothermia, systemic induced hypertension, and barbiturates infusion (Figure 1). Decreased perfusion in a specific cerebral region will result in an initial loss of function. Nevertheless, the loss of function is potentially reversible if immediate intervention is provided. These hypoxic areas of brain tissue, coined as 'ischemic penumbra' by Astrup et al. (11), are dynamic in nature and provide us with an opportunity to act swiftly before the onset of irreversible brain damage $(12,13)$.

\section{Mechanism of action}

Based on the proposed three critical components of the TNP (targeted hypothermia, systemic induced hypertension, and barbiturate infusion), it is postulated that the composite benefit will be synergistic in comparison to the independent components. Targeted hypothermia preserves the ischemic brain section by restricting the penumbral tissue recruitment into the ischemic core. Limitation of the penumbra is achieved by vasoconstriction and subsequent reduction in cerebral edema (14). Maintenance of the blood-brain barrier (BBB) decreases free radical formation, undoubtedly leading to a slowdown of the inflammatory cascade, cell apoptosis, and caspase activation (15). Brain cells will better adapt to the ischemic insult and ATP reduction, with a resultant curtailment in the cerebral metabolic rate of oxygen consumption (CMRO2). Noteworthy, at least $50 \% \mathrm{CMRO} 2$ is required for visible neuro-protection. However, induced hypothermia $\left(34{ }^{\circ} \mathrm{C}\right)$ cannot achieve this specific target alone and lowers CMRO2 by $20 \%$ only (16). Therefore, barbiturate infusion can be safely employed to supplement the reduction in $\mathrm{CMRO} 2$, as it is capable of further lowering the CMRO2 beyond $50 \%$. Finally, induced systolic hypertension, when combined with targeted hypothermia and barbiturate infusion, maintains cerebral perfusion via retrograde carotid flow and an increase in stump pressure. This combination of targeted hypothermia, systemic induced hypertension, and barbiturate infusion during relative cerebral ischemia work together to decrease the demand (low cerebral metabolism and energy consumption) and increase the supply (cerebral blood flow) to maintain the ischemic tissue integrity.

\section{Evidence to support individual components of TNP}

\section{Targeted hypothermia}

Therapeutic hypothermia is a technique of achieving core body temperature between 32 and $34{ }^{\circ} \mathrm{C}$ for medical purposes (15). Brain injury is expected to raise the brain's 
temperature more than the core body temperature (17). Many studies associate increased body temperature with unfavorable outcomes $(18,19)$. Hypothermia in acute ischemic stroke was mainly achieved in the past to manage malignant brain edema (18). However, the utility of hypothermia has been extended in recent times in ischemiareperfusion injury during thrombolysis or mechanical thrombectomy (20).

Targeted therapeutic hypothermia lowers lactate and pyruvate concentrations $(16,21)$. It is capable of decreasing the excitotoxic neurotransmitter glutamate discharge, which results in free radical decrement but accentuates glucose usage by ischemic tissues (22). It also inhibits cellular $\mathrm{Ca} 2+$ influx and reduces peri-infarct depolarization (23). This constellation of active cellular mechanisms suppresses $\mathrm{BBB}$ disruption and decreases edema, thereby, maintaining cerebral autoregulation to reduce post-ischemic hypo or hyperperfusion $(24,25)$. Finally, targeted hypothermia is also believed to modify ischemia associated gene expression (26).

Therapeutic or induced hypothermia has been effective in ischemia-reperfusion injury and cerebral edema. Rapid cooling has been shown to enhance the neurological outcome and overall survival following cardiocirculatory arrest $(27,28)$. Cooling should be maintained as early as possible, preferably within 72 hours before the irreversible tissue damage has initiated $(19,29)$. Although there is a scarcity of focused studies relating to therapeutic hypothermia in ischemic brain injury, its utility has already been established post-cardiac arrest (30-33). A lower metabolic rate will progressively improve global neurological outcomes and reperfusion injury (34). Early cooling has been used in a phase II trial with stroke patients to establish its safety and feasibility (35). Induced therapeutic hypothermia for 1 to 3 days has shown to be effective in dense stroke patients treated without neuro-vascular intervention $(15,30,31)$. COOL AID (36), is the only existing study that employed targeted hypothermia $\left(32{ }^{\circ} \mathrm{C}\right)$ in acute ischemic patients during thrombolysis. Targeted hypothermia proved safe, with the explicit exception of a minor non-critical temporary sinus bradycardia. This study established targeted hypothermia following thrombolysis as a feasible option for neuroprotection in acute stroke.

\section{Controlled induced hypertension}

Perioperative stroke and/or cognitive dysfunction are an established operative risk of CEA, which have been attributed to micro embolism or relative ischemia due to reduced collateral blood supply during carotid artery crossclamping (37-40). Early cognitive dysfunction, evident 24 hours post-surgery, is more prevalent than stroke $(25 \%$ vs. $5 \%)(41,42)$ and results from reduced cerebral blood flow $(43,44)$. To prevent these complications, mean arterial pressure (MAP) is usually kept around 20\% higher than the baseline to maintain collateral blood flow and sustain cerebral perfusion (45-48). Heyer et al. (49) have shown a low risk of early cognitive dysfunction even with MAP $\geq 20 \%$ of the baseline while cross-clamping of the carotid artery.

Cerebral collateral perfusion pressure (CCPP) plays an essential role in avoiding perioperative ischemia. LeSar et al. (50) have already demonstrated the benefit of maintaining permissive hypertension with a significant reduction of operative duration and need for shunting in both awake and sedated patients. Shunting can be avoided in more than two-thirds of the cases, as there are conflicting views and evidence regarding the usefulness of shunting (51). Avoidance can reduce subsequent hazards of the procedure, which can include embolization, occlusion, or increased operative time $(52,53)$. For this reason, we avoided shunting in all our patients.

As maintenance of CCPP is vital to reduce perioperative ischemia, adequate CCPP without the employment of shunts can be made possible with an increment of MAP. Systolic blood pressure maintained between 180-200 mmHg during carotid clamping decreases ischemic stroke risk by increasing collateral blood flow and tissue perfusion across carotid stenosis (49). In TNP, we employ induced systemic hypertension to maintain cerebral perfusion by increasing the retrograde carotid flow and stump pressure in combination with hypothermia and barbiturate infusion.

\section{Barbiturate infusion}

Adequate cerebral blood flow promotes neuronal survival based on the classical supply and demand theory-'the higher the cerebral metabolism, the greater the required blood flow.' Decreasing cerebral metabolic demand will not only require less blood flow but also protects the brain during relative ischemia. There have been many experiments in the past to produce these neuroprotective effects. Barbiturates are the first pharmacological agent to show this favorable metabolic brain effect (54). Barbiturates slow neurotransmission and increase brain adaptability to ischemia (55). Michenfelder et al. (56-58) showed the barbiturate induced dosedependent decrement in the brain's metabolic activity in the 
animal model, with a sequential abatement in EEG activity and ATP depletion. As energy required to produce electrical activity in the brain can be channeled to the surrounding neurons for fulfilling their basal metabolic needs, neuronal energy expenditure is reduced up to half with an isoelectric EEG pattern.

Thiopental was the first to be tried for perioperative neuro-protection (55,59-61). Nussmeier et al. (60) proved 'first-in-humans' cerebral neuroprotection by administering thiopental in a prospective study conducted to assess the neuropsychiatric effect of the barbiturate during cardiopulmonary bypass. In cardiac surgery, barbiturates induce cerebral protection during hypothermic circulatory arrest (62). They have displayed beneficial cerebral effects while performing CEA without adverse cardiovascular outcomes $(63,64)$. They reduce oxygen demand throughout relative tissue ischemia induced by arterial clamping $(65,66)$. Thiopentone has also been demonstrated to provide cerebral protection during CEA and intracranial aneurysm clipping (67). During carotid clamping, Gross et al. (68) used thiopental-induced EEG burst suppression in hypertension unresponsive ischemia, carefully replacing it with technically challenging and dangerous in-line arterial shunting. Young et al. (69) also showed a survival benefit of the prophylactic barbiturate and therapeutic hypothermia in asphyxia.

Although barbiturates have convincingly been shown to maintain arterial, cardiovascular, and cerebral blood flow during focal ischemia, there are many conflicting reports in global ischemia (56,70). Neuroprotection with the barbiturate might not be reproducible with a complete loss of cerebral blood supply. Specifically, it may not be possible to extend these beneficial effects in a condition of total ischemia when the EEG becomes isoelectric within 90 seconds of complete cessation of cerebral blood supply. After that, further depression of EEG activity is neither possible nor relevant $(61,71)$. Nevertheless, during incomplete ischemia as in most unilateral carotid stenosis complicated with tPA failure, this neuroprotective effect can have a significant impact on the patient perioperative survival, and it can be combined effectively with hypothermia and induced systemic hypertension.

\section{Our experience with TNP}

We undertook our first TNP case in 2015 while performing emergency CEA in a 55-year-old man who was referred to us 72 hours after failed tPA. He was in therapeutic inertia despite a 90-99\% ipsilateral carotid stenosis and contralateral occlusion. On presentation, his Rankin and ABCD3-I scores were 4 and 12, respectively. We had two choices, either act or wait. After a thorough discussion with all the concerned stakeholders, including the patient, his family, and surgical staff, we decided to act and explore the possible therapeutic options-emergency CEA with TNP. The patient and his family members were counselled regarding the risk of the procedure and sequelae of the hyper-perfusion syndrome. Consent was obtained, and risk reduction possibilities were carefully discussed with our anesthetic colleagues. All our cases were performed under general anaesthesia because it was not feasible to undertake TNP using local anaesthesia. First, systolic hypertension (200 $\mathrm{mmHg}$ ) was induced, and brain activity suppressed to an iso-electric point with IV barbiturates. After that, a pediatric bronchial suction catheter was used to retrieve thrombus from A1, M1. We did not use a carotid shunt to avoid internal carotid artery embolic dislodgement. Following 24 hours of intubation, the patient was capable of full mobility and self-care, and his Rankin score reverted to 0 . This successful outcome impelled us to apply the triple neuroprotective mechanism in selected patients, whom we previously would have denied surgical interventions after failed tPA or beyond the 24-hour window of opportunity.

It is our usual practice to give a dose of $75 \mathrm{mg}$ of clopidogrel on the evening before surgery in the elective setting. However, in these emergency cases, the surgery took place within hours; therefore, clopidogrel was not given pre-operatively. We did not give high-dose statins because of the associated risk of intracranial hemorrhage, especially in the context of intravenous tPA administration $(72,73)$. Heparin is given intra-operatively (80 IU/kg) before clamping, and this is reversed at the end of surgery with protamine (74). In line with the European Society of Vascular Surgery (ESVS) guidelines, antiplatelet therapy is maintained for the long-term.

Since this first case, we have employed TNP in 25 patients while performing emergency CEA, amongst 12,000 patients referred to us with carotid artery disease between 2015 and 2019 (75). The relatively low procedure count is due to the reservation of the technique for specific patients only, i.e., those who have either failed tPA or those who have passed the recommended time for acute stroke intervention. More than $95 \%$ of the selected cases had $80-99 \%$ stenosis on the ipsilateral side. Following the procedure, there were no incidents of peri-procedural complications, like bleeding, cranial nerve injury, myocardial infarction, or 
death. Twenty-two patients (88\%) were discharged home after a mean hospital stay of 8.4 days while the remaining 3 (12\%) needed long term rehabilitation. Noteworthy, all the patients remained asymptomatic after the first year of follow up.

\section{Discussion}

Mechanical thrombectomy offers a favorable outcome in ischemic stroke patients. However, mechanical thrombectomy in patients with concomitant proximal severe carotid artery disease is time-dependent, and success wanes with therapeutic delay. The possible delay could result from clinical dilemmas after tPA failure, uncertainty about optimal management of proximal internal carotid artery/ common carotid artery disease, and crossing of the 24-hour therapeutic window. Although thrombectomy can be extended up to 24 hours, as per DWI or CTP Assessment with Clinical Mismatch in the Triage of Wake-Up and Late Presenting Strokes Undergoing Neurointervention with Trevo (DAWN) (76) and The Endovascular Therapy Following Imaging Evaluation for Ischemic Stroke (DEFUSE 3) (77) trials, the patient selection remains challenging. For these subgroups of patients, TNP is an innovative technique that employs synergistic utility of credible, evidence-based pragmatic approaches.

TNP can also be a viable option in wake-up stroke (WUS) patients, where patients wake up with stroke after going for routine sleep. WUS patients constitute approximately 15 $30 \%$ of ischemic stroke patients (78-80). It is not possible to clinically pinpoint the exact timing of stroke onset in WUS, leaving clinicians with a therapeutic dilemma $(81,82)$. Unfortunately, there is insufficient evidence for treatment recommendations in these patients, and they are particularly vulnerable to a disability or even death. TNP in these subgroups serves a dual purpose-(I) overcome therapeutic uncertainty, and (II) increase favorable outcomes.

During emergency CEA, surgeons tend to avoid shunts to eliminate the risk of distal embolic dislodgement. At this point, there is a need for an innovative approach to global neural protection resulting from ischemia. Induced therapeutic hypothermia remains a core component of TNP. Cooling during brain surgeries has already proven to be safe and feasible. Targeted therapeutic hypothermia is achieved in a controlled environment and is clinically safe. A Cochrane review by Galvin et al. (83) did not demonstrate any potential harm of induced hypothermia in complex neurosurgery. Targeted hypothermia is already proven in stroke patients. Den Hertog et al. (84) showed a clinically meaningful effect of hypothermia in stroke outcomes. Brain hypothermia can also abate convulsions clinically (85-90). Cold saline has been used to terminate spontaneous electrical and stimulation-evoked brain discharges (91-93). Cooling of the brain has been traditionally achieved either with or without direct brain exposure under sedation or general anesthesia $(85,94-96)$. In a pilot study, Bagić et al. (97) proved the safety of head-neck cooling in awake patients in refractory seizures. In traumatic brain injury, D'Ambrosio et al. (98) and Atkins et al. (99) also showed post-traumatic hypothermia as a viable therapeutic option for seizure reduction. Although all these studies were performed without neurovascular intervention, their safety can be extrapolated to TNP.

Shivering is the most established side effects during induced hypothermia, which can be effectively tackled with anticipation, rewarming therapy (or counter-rewarming), and benzodiazepines (100). About one-half of the patients are likely to suffer from a chest infection, depending on the extent of hypothermia (14). Chest infection risk can be decreased with intubation and mechanical ventilation (101). Although not common, prolonged hypothermia and slow controlled rewarming can also induce cardiac rhythm abnormalities, electrolyte disturbances, and hypoglycemia $(63,102)$. We did not have any of these complications in our patients.

Conventional mechanical thrombus retrieval devices, like MERCI retriever (Stryker, Kalamazoo, MI), the Penumbra system (Penumbra, Alameda, CA), and Solitaire AB (Medtronic, Minneapolis, $\mathrm{MN}$ ) compliment management of acute ischemic patients (103). MERCI retriever devices can be deployed for restoring blood flow in ischemic stroke patients regardless of tPA status (104). The Penumbra system helps in revascularization in large vessel intracranial occlusion (105). The Solitaire AB device, a self-expanding fully retrieval stent, is capable of trapping the clot within the stent matrix. Solitaire $A B$ devices have been proven to have superior outcomes than the MERCI system (106). Recently, mechanical thrombectomy using ADAPT (A Direct Aspiration, First Pass Technique for the Endovascular Treatment of Stroke) has been increasingly used in many vascular institutions (107). A meta-analysis by Phan et al. (108) showed the superiority of ADAPT in comparison to the stent-retriever thrombectomy in terms of complete revascularization and expedited groin to reperfusion time, but without any discernible differences in the clinical outcome. Theoretically, mechanical removal 
of an occluding large vessel thrombus represents the best management strategy (109), but practical limitations persist due to the relative suction sizes and subsequent risk of dislodgement. We employed pediatric bronchial suction (for size advantage) to retrieve thrombus from A1, M1, with a favorable outcome in TNP.

Stroke is the most significant complication in patients undergoing emergency CEA $(110,111)$. Stroke rate can increase based on a multitude of factors, like tangential internal carotid clamping and accidental distal emboli migration to the brain. In our experiences with TNP, we encountered no such complications. We can state with confidence that decreasing the brain metabolic activity by TNP during the hypo-perfused state has reduced the risk of peri-procedural stroke. We only had one diabetic patient amongst the 25 emergency CEAs under TNP. Unfortunately, this diabetic patient suffered from hyperperfusion syndrome but was managed accordingly without any adverse outcome. Although it is relatively premature to infer conclusions based on only one case, we recommend being cautious when operating on people with diabetes as delayed stroke intervention could pose an added risk.

\section{Limitations}

We acknowledge that TNP is still in the early phase and has several functional limitations. There are no controlled comparative studies to objectively compare and back up our claim about patient safety or potential efficacy. Our study was limited in the sample as a sufficiently large sample size for higher statistical power was not feasible in a singlecenter neuro intervention surgical unit. Trials are further limited by specific patient inclusion criteria, medicolegal background, and financial constraints. A prospective multicenter patient registry could be a good choice to report the clinical outcomes. Finally, we understand that the therapeutic benefit seen by us in the last 5 years with TNP cannot be solely attributed to TNP, and a multitude of factors may have contributed to the positive outcomes. For example, the concomitant use of pediatric suction after inducing systolic hypertension for flow reversal could have avoided denuding endothelium by retrieval devices, adding to the safety of this procedure. However, the overwhelming results and absence of visible adverse outcomes in patients who were in therapeutic inertia were encouraging for TNP. Therefore, although there is only preliminary evidence behind the TNP and we do not have Level I Evidence in the form of a randomized controlled trial, we advocate TNP in challenging scenarios-where 'no action' is associated with high disability, and increased morbidity and mortality.

\section{Conclusions}

TNP is a systematic approach consisting of three core components: targeted hypothermia, systemic induced hypertension, and barbiturate infusion and could be a viable option to aid emergency CEA in ischemic stroke patients, specifically for those where tPA has failed and/or the 24-hour therapeutic time window have elapsed. We safely employed TNP in 25 cases during the last 5 years with clinical success. Although our experience suggests TNP as a safe and effective routine therapeutic choice, we advocate for a more extensive controlled comparative study to establish its efficacy and safety.

\section{Acknowledgments}

Funding: None.

\section{Footnote}

Provenance and Peer Review: This article was commissioned by the Guest Editor (Dr. Kosmas I. Paraskevas) for the series "Carotid Artery Stenosis and Stroke: Prevention and Treatment Part I" published in Annals of Translational Medicine. The article was sent for external peer review organized by the Guest Editor and the editorial office.

Conflicts of Interest: All authors have completed the ICMJE uniform disclosure form (available at http://dx.doi. org/10.21037/atm-2020-cass-14). The series "Carotid Artery Stenosis and Stroke: Prevention and Treatment Part I" was commissioned by the editorial office without any funding or sponsorship. The authors have no other conflicts of interest to declare.

Ethical Statement: The authors are accountable for all aspects of the work in ensuring that questions related to the accuracy or integrity of any part of the work are appropriately investigated and resolved.

Open Access Statement: This is an Open Access article distributed in accordance with the Creative Commons Attribution-NonCommercial-NoDerivs 4.0 International License (CC BY-NC-ND 4.0), which permits the non- 
commercial replication and distribution of the article with the strict proviso that no changes or edits are made and the original work is properly cited (including links to both the formal publication through the relevant DOI and the license). See: https://creativecommons.org/licenses/by-nc-nd/4.0/.

\section{References}

1. Fransen PSS, Berkhemer OA, Lingsma HF, et al. Time to Reperfusion and Treatment Effect for Acute Ischemic Stroke: A Randomized Clinical Trial. JAMA Neurol 2016;73:190-6.

2. Saver JL, Goyal M, Bonafe A, et al. Solitaire ${ }^{\mathrm{TM}}$ with the Intention for Thrombectomy as Primary Endovascular Treatment for Acute Ischemic Stroke (SWIFT PRIME) trial: protocol for a randomized, controlled, multicenter study comparing the Solitaire revascularization device with IV tPA with IV tPA alone in acute ischemic stroke. Int J Stroke 2015;10:439-48.

3. Campbell BC, Mitchell PJ, Yan B, et al. A multicenter, randomized, controlled study to investigate EXtending the time for Thrombolysis in Emergency Neurological Deficits with Intra-Arterial therapy (EXTEND-IA). Int J Stroke 2014;9:126-32.

4. Demchuk AM, Goyal M, Menon BK, et al. Endovascular treatment for Small Core and Anterior circulation Proximal occlusion with Emphasis on minimizing CT to recanalization times (ESCAPE) trial: methodology. Int J Stroke 2015;10:429-38.

5. Molina CA, Chamorro A, Rovira A, et al. REVASCAT: a randomized trial of revascularization with SOLITAIRE FR@ device vs. best medical therapy in the treatment of acute stroke due to anterior circulation large vessel occlusion presenting within eight-hours of symptom onset. Int J Stroke 2015;10:619-26.

6. Bracard S, Ducrocq X, Louis Mas J, et al. Mechanical thrombectomy after intravenous alteplase versus alteplase alone after stroke (THRACE): a randomised controlled trial. Lancet Neurol 2016;15:1138-47.

7. 7. Lunagariya A, Patel A, Dalal S, et al. Substantial Rise in tPA Utilization for Acute Ischemic Stroke in the United States Corresponds with Significant Improvement in Outcomes. Stroke 2018;9:ATMP84.

8. Meretoja A, Keshtkaran M, Saver JL, et al. Stroke thrombolysis: save a minute, save a day. Stroke 2014;45:1053-8.

9. Saver JL, Fonarow GC, Smith EE, et al. Time to treatment with intravenous tissue plasminogen activator and outcome from acute ischemic stroke. JAMA 2013;309:2480-8.

10. Hill MD, Hachinski V. Stroke treatment: time is brain. Lancet 1998;352:SIII10-4.

11. Astrup J, Siesjo BK, Symon L. Thresholds in cerebral ischemia - the ischemic penumbra. Stroke 1981;12:723-5.

12. Robinson T, Zaheer Z, Mistri AK. Thrombolysis in acute ischaemic stroke: an update. Ther Adv Chronic Dis 2011;2:119-31.

13. Heiss WD, Kracht LW, Thiel A, et al. Penumbral probability thresholds of cortical flumazenil binding and blood flow predicting tissue outcome in patients with cerebral ischaemia. Brain 2001;124:20-9.

14. Groysman LI, Emanuel BA, Kim-Tenser MA, et al. Therapeutic hypothermia in acute ischemic stroke. Neurosurg Focus 2011;30:E17.

15. Milani WR, Antibas PL, Prado GF. Cooling for cerebral protection during brain surgery. Cochrane Database Syst Rev 2011;10:CD006638.

16. Jaramillo A, Illanes S, Díaz V. Is hypothermia useful in malignant ischemic stroke? Current status and future perspectives. J Neurol Sci 2008;266:1-8.

17. Rossi S, Zanier ER, Mauri I, et al. Brain temperature, body core temperature, and intracranial pressure in acute cerebral damage. J Neurol Neurosurg Psychiatry 2001;71:448-54.

18. Polderman KH. Induced hypothermia and fever control for prevention and treatment of neurological injuries. Lancet 2008;371:1955-69.

19. Polderman KH. Mechanisms of action, physiological effects, and complications of hypothermia. Crit Care Med 2009;37:S186-202.

20. Stocchetti N, Taccone FS, Citerio G, et al. Neuroprotection in acute brain injury: an up-to-date review. Crit Care 2015;19:186.

21. Ji X, Luo Y, Ling F, et al. Mild hypothermia diminishes oxidative DNA damage and pro-death signaling events after cerebral ischemia: a mechanism for neuroprotection. Front Biosci 2007;12:1737-47.

22. Maier CM, Sun GH, Kunis D, et al. Delayed induction and long-term effects of mild hypothermia in a focal model of transient cerebral ischemia: neurological outcome and infarct size. J Neurosurg 2001;94:90-6.

23. Corbett D, Thornhill J. Temperature modulation (hypothermic and hyperthermic conditions) and its influence on histological and behavioral outcomes following cerebral ischemia. Brain Pathol 2000;10:145-52.

24. Nakashima K, Todd MM. Effects of hypothermia on the rate of excitatory amino acid release after ischemic 
depolarization. Stroke 1996; 27:913-8.

25. Timaran CH. McKinsey JF, Schneider PA, et al. Reporting standards for carotid interventions from the Society for Vascular Surgery. J Vasc Surg 2011;53:1679-95.

26. Kollmar R, Schabitz WR, Heiland S, et al. Neuroprotective effect of delayed moderate hypothermia after focal cerebral ischemia: an MRI study. Stroke 2002;33:1899-904.

27. Wu X, Drabek T, Kochanek PM, et al. Induction of profound hypothermia for emergency preservation and resuscitation allows intact survival after cardiac arrest resulting from prolonged lethal hemorrhage and trauma in dogs. Circulation 2006;113:1974-82.

28. Wu X, Drabek T, Tisherman SA, et al. Emergency preservation and resuscitation with profound hypothermia, oxygen, and glucose allows reliable neurological recovery after $3 \mathrm{~h}$ of cardiac arrest from rapid exsanguination in dogs. J Cereb Blood Flow Metab 2008;28:302-11.

29. Yenari MA, Han HS. Neuroprotective mechanisms of hypothermia in brain ischaemia. Nat Rev Neurosci 2012;13:267-78.

30. Nolan JP, Morley PT, Vanden Hoek TL, et al. Therapeutic hypothermia after cardiac arrest: an advisory statement by the advanced life support task force of the International Liaison Committee on Resuscitation. Circulation 2003;108:118-21.

31. Scirica BM. Therapeutic Hypothermia After Cardiac Arrest. Circulation 2013;127:244-50.

32. Neumar RW, Nolan JP, Adrie C, et al. Post-cardiac arrest syndrome: epidemiology, pathophysiology, treatment, and prognostication. A consensus statement from the International Liaison Committee on Resuscitation (American Heart Association, Australian and New Zealand Council on Resuscitation, European Resuscitation Council, Heart and Stroke Foundation of Canada, InterAmerican Heart Foundation, Resuscitation Council of Asia, and the Resuscitation Council of Southern Africa); the American Heart Association Emergency Cardiovascular Care Committee; the Council on Cardiovascular Surgery and Anesthesia; the Council on Cardiopulmonary, Perioperative, and Critical Care; the Council on Clinical Cardiology; and the Stroke Council. Circulation 2008;118:2452-83.

33. Peberdy MA, Callaway CW, Neumar RW, et al. Part 9: post-cardiac arrest care: 2010 American Heart Association Guidelines for Cardiopulmonary Resuscitation and Emergency Cardiovascular Care. Circulation 2010;122:S768-86.
34. European Carotid Surgery Trialists' Collaborative Group. Endarterectomy for moderate symptomatic carotid stenosis: interim results from the MRC European Carotid Surgery Trial. Lancet 1996;347:1591-3.

35. Candela S, Dito R, Casolla B, et al. Hypothermia during Carotid Endarterectomy: A Safety Study. PLoS One 2016;11:e0152658.

36. Krieger DW, De Georgia MA, et al. Cooling for acute ischemic brain damage (COOL AID): an open pilot study of induced hypothermia in acute ischemic stroke. Stroke 2001;32:1847-54.

37. de Borst GJ, Moll FL, van de Pavoordt HD, et al. Stroke from carotid endarterectomy: when and how to reduce perioperative stroke rate? Eur J Vasc Endovasc Surg 2001;21:484-9.

38. Ackerstaff RG, Jansen C, Moll FL, et al. The significance of microemboli detection by means of transcranial Doppler ultrasonography monitoring in carotid endarterectomy. J Vasc Surg 1995;21:963-9.

39. Ferguson GG, Eliasziw M, Barr HW, et al. The North American Symptomatic Carotid Endarterectomy Trial : surgical results in 1415 patients. Stroke 1999;30:1751-8.

40. Krul JM, van Gijn J, Ackerstaff RG, et al. Site and pathogenesis of infarcts associated with carotid endarterectomy. Stroke 1989;20:324-8.

41. Heyer EJ, Adams D, Todd G, et al. Neuropsychometric changes in patients after carotid endarterectomy. Stroke 1998;29:1110-5.

42. Heyer EJ, Sharma R, Rampersad A, et al. A controlled prospective study of neuropsychological dysfunction following carotid endarterectomy. Arch Neurol 2002;59:217-22.

43. Costin M, Rampersad A, Solomon RA, et al. Cerebral injury predicted by transcranial Doppler ultrasonography but not electroencephalography during carotid endarterectomy. J Neurosurg Anesthesiol 2002;14:287-92.

44. Mergeche JL, Bruce SS, Sander Connolly E, et al. Reduced middle cerebral artery velocity during cross-clamp predicts cognitive dysfunction after carotid endarterectomy. J Clin Neurosci 2014;21:406-11.

45. Boysen G, Ladegaard-Pedersen HJ, Valentin N, Engell HC. Cerebral blood flow and internal carotid artery flow during carotid surgery. Stroke 1970;1:253-60.

46. Antunes M, Biala G. The novel object recognition memory: neurobiology, test procedure, and its modifications. Cogn Process 2012;13:93-110.

47. Smith JS, Roizen MF, Cahalan MK, et al. Does anesthetic technique make a difference? Augmentation of systolic 
blood pressure during carotid endarterectomy: effects of phenylephrine versus light anesthesia and of isoflurane versus halothane on the incidence of myocardial ischemia. Anesthesiology 1988;69:846-53.

48. Howell SJ. Carotid endarterectomy. Br J Anaesth 2007;99:119-31.

49. Heyer EJ, Mergeche JL, Anastasian ZH, et al. Arterial blood pressure management during carotid endarterectomy and early cognitive dysfunction. Neurosurgery 2014;74:245-51.

50. LeSar CJ, Sprouse LR, Harris WB. Permissive hypertension during awake eversion carotid endarterectomy: a physiologic approach for cerebral protection. J Am Coll Surg 2014;218:760-6.

51. Gumerlock MK, Neuwelt EA. Carotid endarterectomy: to shunt or not to shunt. Stroke 1988;19:1485e1490.

52. Ferguson GG. Carotid endarterectomy. To shunt or not to shunt? Arch Neurol 1986;43:615e617.

53. Browse NL, Ross-Russell R. Carotid endarterectomy and the Javid shunt: the early results of 215 consecutive operations for transient ischaemic attacks. Br J Surg 1984;71:53e57.

54. Bilotta F, Stazi E, Zlotnik A, Gruenbaum SE, Rosa G. Neuroprotective effects of intravenous anesthetics: a new critical perspective. Curr Pharm Des 2014;20:5469-75.

55. Goldstein A, Wells BA, Keats AS. Increased tolerance to cerebral anoxia by pentobarbital. Arch Int Pharmacodyn Ther 1966;161:138-43.

56. Michenfelder JD, Milde JH, Sundt TM. Cerebral protection by barbiturate anesthesia. Use of middle cerebral artery occlusion in Java Monkeys. Arch Neurol 1976;33:345-50.

57. Michenfelder JD, Theye R. Cerebral protection by thiopental during hypoxia. Anesthesiology 1973;39:510-7.

58. Michenfelder JD. The interdependency of cerebral function and metabolic effects following massive doses of thiopental in the dog. Anesthesiology 1974;41:231-6.

59. Kofke WA, Nemoto EM, Hossmann KA, et al. Brain blood flow and metabolism after global ischemia and post-insult thiopental therapy in monkeys. Stroke 1979;10:554-60.

60. Nussmeier NA, Arlund C, Slogoff S. Neuropsychiatric complications after cardiopulmonary bypass: cerebral protection by a barbiturate. Anesthesiology 1986;64:165-70.

61. Zaidan JR, Klochany A, Martin W, et al. Effect of thiopental on neurologic outcome following coronary artery bypass grafting. Anesthesiology 1991;74:406-11.
62. Hirotani T, Kameda T, Kumamoto T, et al. Protective effect of thiopental against cerebral ischemia during circulatory arrest. Thorac Cardiovasc Surg 1999;47:223-8.

63. Hicks RG, Kerr DR, Horton DA. Thiopental cerebral protection under EEG control during carotid endarterectomy. Anaesth Intensive Care 1986;14:22-8.

64. Markowitz IP, Adinolfi MF, Kerstein MD. Barbiturate therapy in the postoperative endarterectomy patient with a neurologic deficit. Am J Surg 1984;148:221-3.

65. Dietrichs ES, Dietrichs E. Neuroprotective effects of hypothermia. Tidsskr Nor Laegeforen 2015;135:1646-51.

66. McMeniman WJ, Fletcher JP, Little JM. Experience with barbiturate therapy for cerebral protection during carotid endarterectomy. Ann R Coll Surg Engl 1984;66:361-4.

67. McConkey PP, Kien ND. Cerebral protection with thiopentone during combined carotid endarterectomy and clipping of intracranial aneurysm. Anaesth Intensive Care 2002;30:219-22.

68. Gross CE, Adams HP Jr, Sokoll MD, et al. Use of anticoagulants, electroencephalographic monitoring, and barbiturate cerebral protection in carotid endarterectomy. Neurosurgery 1981;9:1-5.

69. Young L, Berg M, Soll R. Prophylactic barbiturate use for the prevention of morbidity and mortality following perinatal asphyxia. Cochrane Database Syst Rev 2016;5:CD001240.

70. Hoff JT, Smith AL, Hankinson HL, et al. Barbiturate protection from cerebral infarction in primates. Stroke $1975 ; 6: 28-33$

71. Baughman VL. Brain protection during neurosurgery. Anesthesiol Clin North Am 2002;20:315-27.

72. Scheitz JF, Seiffge DJ, Tütüncü S, et al. Dose-related effects of statins on symptomatic intracerebral hemorrhage and outcome after thrombolysis for ischemic stroke. Stroke 2014;45:509-14.

73. Goldstein LB, Amarenco P, Zivin J, et al. Stroke Prevention by Aggressive Reduction in Cholesterol Levels Investigators. Statin treatment and stroke outcome in the Stroke Prevention by Aggressive Reduction in Cholesterol Levels (SPARCL) trial. Stroke 2009;40:3526-31.

74. Naylor AR, Ricco JB, de Borst GJ, et al. Editor's Choice - Management of Atherosclerotic Carotid and Vertebral Artery Disease: 2017 Clinical Practice Guidelines of the European Society for Vascular Surgery (ESVS). Eur J Vasc Endovasc Surg 2018;55:3-81.

75. Sultan S, Dulai M, Laffey J, et al. Triple Neuroprotection With Targeted Hypothermia, Controlled Induced Hypertension and Barbiturate Infusion During Emergency 
Carotid Endarterectomy for Acute Stroke. Eur J Vasc

Endovasc Surg 2019;58:e625-6.

76. Nogueira RG, Jadhav AP, Haussen DC, et al. Thrombectomy 6 to 24 Hours after Stroke with a Mismatch between Deficit and Infarct. N Engl J Med 2018;378:11-21.

77. Albers GW, Marks MP, Kemp S, et al. Thrombectomy for Stroke at 6 to 16 Hours with Selection by Perfusion Imaging. N Engl J Med 2018;378:708-18.

78. Boode B, Welzen V, Franke C, et al. Estimating the number of stroke patients eligible for thrombolytic treatment if delay could be avoided. Cerebrovasc Dis 2007;23:294-8.

79. Koton S, Tanne D, Bornstein NM, et al. Ischemic stroke on awakening: patients' characteristics, outcomes and potential for reperfusion therapy. Neuroepidemiology 2012;39:149-53.

80. Bornstein NM, Gur AY, Fainshtein P, et al. Stroke during sleep: epidemiological and clinical features. Cerebrovasc Dis 1999;9:320-2.

81. Buck D, Shaw LC, Price CI, et al. Reperfusion therapies for wake-up stroke: systematic review. Stroke 2014;45:1869-75.

82. Rubin MN, Barrett KM. What to do With Wake-Up Stroke. Neurohospitalist 2015;5:161-72.

83. Galvin IM, Levy R, Boyd JG, et al. Cooling for cerebral protection during brain surgery. Cochrane Database Syst Rev 2015;1:CD006638.

84. Den Hertog HM, van derWorp HB, Tseng MC, et al. Cooling therapy for acute stroke. Cochrane Database Syst Rev 2009;1:CD001247.

85. Vastola EF, Homan R, Rosen A. Inhibition of focal seizures by moderate hypothermia: a clinical and experimental study. Arch Neurol 1969;20:430-9.

86. Yang XF, Duffy DW, Morley RE, et al. Neocortical seizure termination by focal cooling: temperature dependence and automated seizure detection. Epilepsia 2002;43:240-5.

87. Yang XF, Chang JH, Rothman SM. Intracerebral temperature alterations associated with focal seizures. Epilepsy Res 2002;52:97-105.

88. Yang XF, Chang JH, Rothman SM. Long-lasting anticonvulsant effect of focal cooling on experimental neocortical seizures. Epilepsia 2003;44:1500-5.

89. Rothman SM, Smyth MD, Yang XF, et al. Focal cooling for epilepsy: an alternative therapy that might actually work. Epilepsy Behav 2005;7:214-21.

90. Yang XF, Rothman SM. Focal cooling rapidly terminates experimental neocortical seizures. Ann Neurol
2001;49:721-6.

91. Ku YTE, Montgomery LD, Webbon BW. Hemodynamic and thermal responses to head and neck cooling in men and women. Am J Phys Med Rehabil 1996;75:443-50.

92. Hill MW, Wong M, Amarakone A, et al. Rapid cooling aborts seizure-like activity in rodent hippocampalentorhinal slices. Epilepsia 2000;41:1241-8.

93. Karkar KM, Garcia PA, Bateman LM, et al. Focal cooling suppresses spontaneous epileptiform activity without changing the cortical motor threshold. Epilepsia 2002;43:932-5.

94. Wang H, Olivero W, Lanzino G, et al. Rapid and selective cerebral hypothermia achieved using a cooling helmet. J Neurosurg 2004;100:272-7.

95. Sourek K, Travnicek V. General and local hypothermia of the brain in the treatment of intractable epilepsy. J Neurosurg 1970;33:253-9.

96. Sartorius CJ, Berger MS. Rapid termination of intraoperative stimulation-evoked seizures with application of cold Ringer's lactate to the cortex. Technical Note. J Neurosurg 1998;88:349-51.

97. Bagić A, Theodore WH, Boudreau EA, et al. Towards a non-invasive interictal application of hypothermia for treating seizures: a feasibility and pilot study. Acta Neurol Scand 2008;118:240-4.

98. D'Ambrosio R, Eastman CL, Darvas F, et al. Mild passive focal cooling prevents epileptic seizures after head injury in rats. Ann Neurol 2013;73:199-209.

99. Atkins CM, Truettner JS, Lotocki G, et al. Post-traumatic seizure susceptibility is attenuated by hypothermia therapy. Eur J Neurosci 2010;32:1912-20.

100. Froehler MT, Ovbiagele B. Therapeutic hypothermia for acute ischemic stroke. Expert Rev Cardiovasc Ther 2010;8:593-603.

101.Hong JM, Lee JS, Song HJ, et al. Therapeutic hypothermia after recanalization in patients with acute ischemic stroke. Stroke 2014;45:134-40.

102. Rinehart TW, Merkel MJ, Schulman PM, et al. Therapeutic Hypothermia after Perioperative Cardiac Arrest in Cardiac Surgical Patients. ICU Dir 2012;3:271-8.

103. Baker WL, Colby JA, Tongbram V, et al.

Neurothrombectomy Devices for Treatment of Acute Ischemic Stroke. Rockville (MD): Agency for Healthcare Research and Quality; 2011 Jan. (Comparative Effectiveness Technical Briefs, No. 4.) Results.

104. Becker KJ, Brott TG. Approval of the MERCI Clot

Retriever: a critical review. Stroke 2005;36:400-3. 105.Penumbra Pivotal Stroke Trial Investigators. The 
penumbra pivotal stroke trial: safety and effectiveness of a new generation of mechanical devices for clot removal in intracranial large vessel occlusive disease. Stroke 2009; 40:2761-8.

106. Saver JL, Jahan R, Levy EI, et al. Solitaire flow restoration device versus the Merci Retriever in patients with acute ischaemic stroke (SWIFT): a randomised, parallel-group, non-inferiority trial. Lancet 2012;380:1241-9.

107. Turk AS, Frei D, Fiorella D, et al. ADAPT FAST study: a direct aspiration first pass technique for acute stroke thrombectomy. J Neurointerv Surg 2014;6:260-4.

108. Phan K, Dmytriw AA, Teng I, et al. A direct aspiration first pass technique vs standard endovascular therapy

Cite this article as: Sultan S, Acharya Y, Barrett N, Hynes N. A pilot protocol and review of triple neuroprotection with targeted hypothermia, controlled induced hypertension, and barbiturate infusion during emergency carotid endarterectomy for acute stroke after failed tPA or beyond 24-hour window of opportunity. Ann Transl Med 2020;8(19):1275. doi: 10.21037/ atm-2020-cass-14 for acute stroke: a systematic review and meta-analysis. Neurosurgery 2018;83:19-28.

109. Park H. A suction thrombectomy technique: a rapid and effective method for intra-arterial thrombolysis. J Cerebrovasc Endovasc Neurosurg 2015;17:13-9.

110.Faateh M, Dakour-Aridi H, Kuo PL, et al. Risk of emergent carotid endarterectomy varies by type of presenting symptoms. J Vasc Surg 2019;70:130-137.e1.

111.Knappich C, Kuehnl A, Tsantilas P, et al. Patient characteristics and in-hospital outcomes of emergency carotid endarterectomy and carotid stenting after stroke in evolution. J Vasc Surg 2018;68:436-44.e6. 